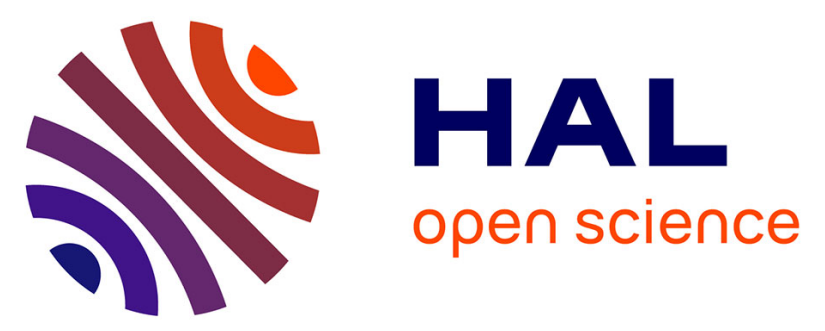

\title{
Effect of angle deposition $\gamma$ on the structural, optical and electrical properties of copper oxide zigzag $(+\gamma,-\gamma)$ nanostructures elaborated by glancing angle deposition
}

\author{
F. Chaffar Akkari, H. Ben Jbara, D. Abdelkader, B. Gallas, M. Kanzari
}

\section{- To cite this version:}

F. Chaffar Akkari, H. Ben Jbara, D. Abdelkader, B. Gallas, M. Kanzari. Effect of angle deposition $\gamma$ on the structural, optical and electrical properties of copper oxide zigzag $(+\gamma,-\gamma)$ nanostructures elaborated by glancing angle deposition. Thin Solid Films, 2018, 657, pp.61-69. 10.1016/j.tsf.2018.05.006 . hal-01930102

\section{HAL Id: hal-01930102 \\ https://hal.sorbonne-universite.fr/hal-01930102}

Submitted on 21 Nov 2018

HAL is a multi-disciplinary open access archive for the deposit and dissemination of scientific research documents, whether they are published or not. The documents may come from teaching and research institutions in France or abroad, or from public or private research centers.
L'archive ouverte pluridisciplinaire HAL, est destinée au dépôt et à la diffusion de documents scientifiques de niveau recherche, publiés ou non, émanant des établissements d'enseignement et de recherche français ou étrangers, des laboratoires publics ou privés. 


\title{
Effect of angle deposition $\gamma$ on the structural, optical and electrical properties of copper oxide zigzag $(+\gamma,-\gamma)$ nanostructures elaborated by glancing angle deposition
}

\author{
F. Chaffar Akkari ${ }^{1 *}$, H. Ben Jbara ${ }^{1}$, D. Abdelkader ${ }^{1}$, B. Gallas ${ }^{2}$, M. Kanzari ${ }^{1,3}$ \\ ${ }^{1}$ Université Tunis ElManar, Ecole Nationale d'Ingénieurs de Tunis, Laboratoire \\ de Photovoltaïque et Matériaux Semiconducteurs, BP37, 1002 Le Belvédère, Tunis, Tunisia \\ ${ }^{2}$ Sorbonne Université, CNRS, Institut des NanoSciences de Paris - UMR 7588 \\ Campus Pierre et Marie Curie, Case 840, 04 place Jussieu 75005 Paris, France \\ ${ }^{3}$ Université de Tunis, Institut Préparatoire aux Etudes d'Ingénieurs de Tunis-IPEIT, 2, Rue Jawaher Lel Nehru, 1089 \\ Montfleury, Tunisia \\ * Corresponding author: ferid.chaffarakkari@ipeiem.utm.tn
}

\begin{abstract}
In this work, $\mathrm{Cu}_{\mathrm{x}} \mathrm{O}$ thin films were obtained by air annealing of copper thin films deposited on glass substrates using thermal evaporation method by Glancing Angle Deposition "GLAD" technique. The copper was sculptured into a zigzag shape, which presents two columns with inclined angles $+\gamma$ and $-\gamma$ where $\gamma$ is the deposition angle between the incident flux and the substrate normal. Morphological, structural, optical and electrical properties of the obtained thin films were investigated using X-ray diffraction (XRD), UV-Vis-NIR Spectroscopy and electrical resistivity measurements. The XRD patterns revealed that thin films deposited at different incident angles are mainly crystallized in $\mathrm{Cu}_{2} \mathrm{O}$ cubic phase characterized by the preferential orientation along (111) plane. The optical parameters were calculated from the analysis of the transmittance and reflectance spectra in the wavelength range 300-1800 $\mathrm{nm}$. The absorption coefficient exceeds $10^{5} \mathrm{~cm}^{-1}$ in the visible and NIR spectral ranges. Direct band gap energy increases from 2 to $2.54 \mathrm{eV}$ with deposition angle. The in-plane birefringence and the anisotropic resistivity of the $\mathrm{Cu}_{2} \mathrm{O}$ films were also studied. Their maxima were obtained at incident flux angle of $\gamma= \pm 60^{\circ}$. Therefore, the GLAD technique is a promising way to create zigzag nanostructures with enhanced anisotropic properties.
\end{abstract}

Keywords 
Glancing angle deposition, zigzag columns, electrical anisotropy, copper oxide, $\mathrm{Cu}_{2} \mathrm{O}$, thermal evaporation.

\section{Introduction}

In the recent years, glancing angle deposition (GLAD) technique has attracted interest for designing novel structures of thin films and controlling their morphologies and physicochemical properties [1,2]. This technique is a physical vapor deposition (PVD) process that is implemented by oblique angle deposition and/or substrate rotation in front of the deposition source to control the column orientation and porosity of nanostructured films $[3,4]$. The GLAD technique has been shown to be capable of thin films elaboration with a wide variety of microstructures, such as vertical columns [5], helical [6], and zigzag shapes [7], which is hardly obtained from the normal incidence vapor deposition [8].

For instance, films with a porous structure have been shown to well operate in various applications such as solar cell [9], photonic crystals [10], optical filters [11], gas sensors [12] and photo-catalysis [13]. Thus, many novel physical and chemical properties of thin films can also be easily engineered [14].

Copper oxides $\left(\mathrm{Cu}_{\mathrm{x}} \mathrm{O}\right)$ have gained extensive interest because of its important role in many applications, such as catalyst [15], gas sensor [16], optical and optoelectronic devices [17]. Especially, $\mathrm{Cu}_{\mathrm{x}} \mathrm{O}$ thin films are potential for photovoltaic applications, due to their good properties such as high absorption coefficient in the visible region, elemental abundance, non-toxicity and stability with the characteristic of being "ultra-low-cost". Their direct optical band gap energy is in the range of (2.1 to $2.6 \mathrm{eV})$ for $\mathrm{Cu}_{2} \mathrm{O}$ and (1.21 to $\left.2.1 \mathrm{eV}\right)$ for $\mathrm{CuO}$ [18-22]. Copper oxide thin films had been fabricated by various techniques such as electrodeposition [23], pulsed laser deposition [24], sol-gel technique [21], spay pyrolysis [25] ...etc. However, the common technique used is thermal evaporation due to its simplicity, low cost, reproducibility, ease of composition control and large area deposition. In a previous work, copper oxide nanostructures were developed into inclined nanostructures using a deposition angle of $+85^{\circ}$ and two zigzag shapes using $\left(+85^{\circ},-85\right)(2$ 
directions $)$ and $\left(+85^{\circ},-85,+85^{\circ}\right)(3$ directions $)$ where $\gamma=85^{\circ}$ is the deposition angle between the incident flux direction and the substrate surface normal [26]. Another earlier work, where nanorod structures tilted toward the incident deposition direction were made with a stationary substrate at various deposition angles from 0 to $80^{\circ}$ [27]. In the two previous works, the substrate does not rotate around its own axis. In this actual work, copper thin films were prepared by thermal vacuum evaporation method with the GLAD technique, proceeding with double inclined angles $+\gamma$ and $-\gamma$ just by rotating the substrate holder with azimuthal angle $\phi=180^{\circ}$, in order to develop zigzag shapes. Then they were annealed in air, to form copper oxides films. In this paper, we aim therefore to investigate the influence of incident flux angles $\pm \gamma$ on the structural, optical and electrical properties of these samples. According to these properties, one can optimize the angle of deposition of $\mathrm{Cu}_{2} \mathrm{O}$ nanostructures for a potential application such as gas sensing devices, since the gas atoms can infiltrate easily in nano-structures or photovoltaic solar cells since its band gap energy is suitable for buffer layer in solar cell structure.

\section{Experimental details}

The glass substrates were previously cleaned by washing agents (a commercial detergent, acetone, a solution of diluted hydrochloric acid then rinsed with ethanol and deionized water) before being introduced into the vacuum system. Copper thin films were grown on glass substrates of rectangular shape $\left(2.5 \times 1.5 \mathrm{~cm}^{2}\right)$ by vacuum thermal evaporation using the GLAD technique from a tungsten boat. The substrates were placed above the source at a distance of $11 \mathrm{~cm}$. The level of base pressure achieved before the deposition was $5 \times 10^{-5}$ Torr. During our experiments, the deposition angle $\gamma$, which is defined as the angle between the incident flux direction and the substrate normal, had taken the following values $\pm 40^{\circ}, \pm 60^{\circ}, \pm 75^{\circ}$ and $\pm 85^{\circ}$. A motorized substrate holder ensured the rotation of the substrate, in order to form $+\gamma$ then $-\gamma$ angles. The evaporation is stopped during the rotation of the substrate holder with azimuthal angle $\phi=180^{\circ}$. A schematic drawing of the film deposition system is shown in Fig. 1. The obtained films were inserted into a programmable furnace, and annealed at $250{ }^{\circ} \mathrm{C}$ during 2 hours, in order to obtain copper oxide 
films. The zigzag nanostructures were characterized by scanning electron microscopy SEM (Zeiss ultra 55 microscope) with an operating voltage equal to $5 \mathrm{kV}$. The crystalline phase and crystal orientation of the GLAD films were examined using a Philips X'Pert X-ray diffractometer with monochromatic $\mathrm{CuK}_{\alpha}$ radiation $(\lambda=0.154056 \mathrm{~nm}$ and $40 \mathrm{kV}, 30 \mathrm{~mA})$ in the $2 \theta$ range $20^{\circ}-70^{\circ}$. Optical measurements, reflectance, and transmittance, of the obtained films, were carried out by means of UV-Vis-NIR spectroscopy. The wavelength accuracy is $1 \mathrm{~nm}$ in the wavelength region 300-1800 nm by using a spectrophotometer (Shimadzu $3100 \mathrm{~S}$ ). The photometric accuracy of these measurements is $\pm 3 \%$. The attained optical constants estimation errors depend on the $R$ measurement accuracy. The experiment was done twice and the nano-zigzag structures were observed in both cases for the same values of deposition angles.

\section{Results and discussion}

\subsection{Morphological properties}

Fig.2.a and b show highly arranged nano-zigzags copper structure deposited at an angle $\gamma= \pm 85$ ${ }^{\circ}$ and $\gamma= \pm 60^{\circ}$, respectively. It depicts void separated nano-zigzags; this space becomes greater for the high deposition angles because of the important shadowing effect produced by the GLAD technique, which is the most heuristic phenomenon for the nanostructures elaborated by GLAD. The shadowing phenomenon begins as soon as the vapor of the material begins to reach the inclined substrate. The first ad-atoms inhibit the incoming atoms that try to reach the substrate and consequently cover a neighboring region of the substrate. The incoming atoms will be forced to stick on the first ad-atoms and the "nano-rods" begin to be created each time the atoms try to reach the substrate and are prohibited by the top of the formed clusters. The films adhere well to the substrates and there is not a detachment phenomenon, in spite of the observed voids by the SEM images. The effect of annealing on the deposited copper samples is clear as shown in Fig.2.c and d. The nanostructures become denser because of the incorporation of oxygen into the inter-motif space. As the shadowing effect is appreciable at high deposition angles, the incorporation of oxygen becomes easier and it reaches more depth. It is for this reason that the oxidation is found to be 
perfect for the sample deposited at $\gamma= \pm 85^{\circ}$, as shown in Fig.2.c. The example of Fig.2.d shows that there are two parts; the upper part of the nano-zigzags has been perfectly oxidized, the lower part is also sufficiently oxidized but not with the same reach. This is due to the shadowing effect, which is not good enough for ordinary and weak angles of deposition and consequently, the oxidation does not occur with the same magnitude. Obviously, the annealing affects the surface state. The SEM images in Fig.3.a and $\mathbf{b}$ - taken at two different magnifications - show a porous surface of nano-zigzags of copper deposited at $\gamma= \pm 85^{\circ}$. While Fig.3.c and $\mathbf{d}$ show the changes occurred on the surface by annealing effect, it is clear that it becomes a compact surface by oxidation.

Several works have attempted to synthesize $\mathrm{Cu}_{2} \mathrm{O}$ nanostructures using chemical methods [2830] like solvothermal method [28]. Z. Cheng et al. [29] achieved a simple and highly repeatable wet chemical approach for the synthesis of $\mathrm{Cu}_{2} \mathrm{O}$ nanorods. Apart from chemical methods, PVD processes were also used to create $\mathrm{Cu}_{2} \mathrm{O}$ nanorods array by anodic oxidation [31]. Nevertheless, in almost all cases, the nanorods are randomly oriented, and thus, physical properties of the sample seem to be isotropic. The GLAD technique makes it possible to develop highly oriented nanostructures, which is an advantage that characterizes this technique and enhances or creates anisotropic properties.

\subsection{Structural properties}

The XRD measurements were used to study the structural properties of air annealed $\mathrm{Cu}$ thin films deposited on glass substrates and prepared by GLAD technique. Fig.4.a shows the XRD patterns of $\mathrm{Cu}_{\mathrm{x}} \mathrm{O}$ thin films deposited respectively at $\gamma= \pm 40^{\circ}, \pm 60^{\circ}, \pm 75^{\circ}$ and $\pm 85^{\circ}$. It can be seen that the $\mathrm{Cu}_{\mathrm{x}} \mathrm{O}$ thin films are strongly grown along the (111) direction at $2 \theta=36.5^{\circ}$, which indicates a preferential orientation of the $\mathrm{Cu}_{2} \mathrm{O}$ cubic phase according to the JCPDS card number (01-0782076) and the RRUFF ID: R050384.1. Besides, we note the appearance of (111) peak assigned to $\mathrm{CuO}$ monoclinic phase (JCPDS 45-0937 and RRUFF ID: R120076.9) at $2 \theta=38.7^{\circ}$, in addition to $\mathrm{Cu}_{2} \mathrm{O}$ peaks, at deposition angle $\gamma= \pm 75^{\circ}$. The relative intensity of the main peak decreases from 
1400 to 525 (cps) with increasing the deposition angle. As shown in Fig.4.b, the intensity ratio $\mathrm{I}_{111} /$ $\mathrm{I}_{200}$ decreases as a function of the incident flux angle, which indicates that the degree of crystallinity of the $\mathrm{Cu}_{2} \mathrm{O}$ zigzag thin films has gradually reduced at larger inclination angles. We reported in our previous work [26] that the zigzag configuration $\left(+85^{\circ},-85^{\circ},+85^{\circ}\right)$ enhances the crystallinity, comparing with $\left(+85^{\circ},-85^{\circ}\right)$ and $+85^{\circ}$ configurations, contrary to the present work. The effect of angle deposition to produce nanorod architectures not zigzag shape was studied and it was shown that the maximum intensity of the main peaks (111) assigned to the two phases $\mathrm{Cu}_{2} \mathrm{O}$ and $\mathrm{CuO}$ was achieved for an angle of $60^{\circ}$ [27]. The actual zigzag shape given in the present work proves to be an inhibitor of copper oxidation and the oxygen surface diffusion mechanism seems to be held up. Since, the temperature is an important parameter in the kinetic of the oxidation stage [27], we guess therefore that, the experiment conditions $\left(250^{\circ}+2\right.$ hours $)$ may not be suitable for enhancement of the intensity of the (111) peak of the copper oxide phases for the actual zigzag configuration $(+\gamma,-$ $\gamma$ ) for $\gamma>60^{\circ}$. Although $\mathrm{CuO}$ is a secondary phase and appears only for the sample deposited at 75 ${ }^{\circ}$, it would be interesting to try other annealing times (thermal oxidation) less than 2 hours to avoid the formation of the blends of $\mathrm{CuO}$ and $\mathrm{Cu}_{2} \mathrm{O}$. Because during the increase of the temperature there is a formation of the $\mathrm{Cu}_{2} \mathrm{O}$ phase on the surface of the copper films. Because of a difference in lattice parameters and so the cell volume of copper and its oxide, this creates a high compressive stress that leads to a high density of grain boundaries of this phase [32]. These conditions with long oxidation times, convert the top layer of $\mathrm{Cu}_{2} \mathrm{O}$ phase into $\mathrm{CuO}$ phase, particularly in the form of nanostructures. Regarding, the intensity ratio $\mathrm{I}_{111} / \mathrm{I}_{200}$, we found that the same behavior of this ratio was shown in a recent study on electroplated $\mathrm{Cu}$ films on a Si-interposer substrate exposed in an air environment [33]. The decrease of $\mathrm{I}_{111} / \mathrm{I}_{200}$ ratio of the electroplated $\mathrm{Cu}$ thin film was observed when the exposure time is between 31 and 58 days, which demonstrates that atoms in these samples were rearranged at room temperature from an as-electroplated-Cu film, which is generally unstable [33]. The ratio $\mathrm{I}_{111} / \mathrm{I}_{200}$ of the redistribution layer-Cu (RDL) films decreases from relatively strong 
3.7 to 2.7 through self-rearrangement [33]. In the present study, this ratio reaches a value slightly below 2, but it does not require a period longer than 31 days.

In order to study more the structural properties of the elaborated samples, the crystallite size $D$ of the films was calculated using Scherrer's formula defined as [34]:

$$
D=\frac{0.9 \lambda}{\beta \cos \theta}
$$

where $D$ is the average crystallite size, $\lambda$ the wavelength of $\mathrm{CuK}_{\alpha}$ radiation, $\beta$ is the full width at half maximum and $\theta$ is the Bragg angle. As seen in Table 1, the crystallite size decreases with the increase of incident angle. In the Scherrer's formula, the crystallite size $D$ has been determined using a Gaussian function to fit the peaks in the XRD patterns. Then, to remove the effect of broadening from XRD machine, the presence of micro-strain and/or extended defects (stacking faults, micro-twinning, dislocations, etc.) [35,36], we used the Williamson-Hall method. The total broadening $\beta_{t o t}$ is given by the following equations:

$$
\begin{gathered}
\beta_{\text {tot }}^{2}=\beta_{\text {crystallite }}^{2}+\beta_{\text {strain }}^{2}+\beta_{\text {instr }}^{2} \\
\left(\beta_{\text {tot }}^{2}-\beta_{\text {instr }}^{2}\right) \cos ^{2} \theta=\left(\frac{0.9 \lambda}{D_{W H}}\right)^{2}+(4 \varepsilon \sin \theta)^{2}
\end{gathered}
$$

where $\varepsilon$ is the strain (micro-deformation), $\beta_{\text {instr }}=0.02^{\circ}$ is the instrumental broadening and $D_{W H}$ is the crystalline size of Williamson-Hall method. When we plot $\left\{\left(\beta^{2}{ }_{t o t}-\beta^{2}{ }_{\text {instr }}\right) \cos ^{2} \theta\right\}$ versus $\sin ^{2} \theta$, we get a linear curve with a slope $(4 \varepsilon)^{2}$ and intercept $\left(\frac{0.9 \lambda}{D_{W H}}\right)^{2}$. From the slope, the strain is calculated and it varies between $8.63 \times 10^{-3}$ and $11.45 \times 10^{-3}$. The largest strain value is attained for the deposition angle $\gamma=75^{\circ}$ which exhibits the lowest ratio $I_{111} / I_{200}$. The most probable reason is due to the apparition of the monoclinic $\mathrm{CuO}$ phase (in $\gamma= \pm 75^{\circ}$ ) that may exert an additional constraint on the (111) planes of $\mathrm{Cu}_{2} \mathrm{O}$ (cubic). From the intercept, we can calculate the crystallite 
size, which decreases from 27 to $21 \mathrm{~nm}$. The results are resumed in Table 1. The crystallite size obtained by the Scherrer's formula was less than that obtained by the Williamson-Hall method because the strain correction factor has been taken into account in the case of the Williamson-Hall method, whereas not in the case of the Scherrer's method.

\subsection{Optical properties}

In order to investigate the effect of the deposition angle $\pm \gamma$ on the optical properties of the $\mathrm{Cu}_{\mathrm{x}} \mathrm{O}$ zigzag nanostructured thin films, their optical parameters such as transmittance, reflectance, absorption coefficient, refractive index, optical band gap, birefringence and Urbach energy were studied.

Fig. 5 illustrates the transmittance $T$ and reflectance $R$ spectra of $\mathrm{Cu}_{\mathrm{x}} \mathrm{O}$ zigzag thin films deposited at different incident angles in the wavelength range 300-1800 $\mathrm{nm}$. The spectra reveal interference effects in the transparency region 500-1800 nm with a fall of transmittance at the band edge, whereas the interference effect disappears in the region of very strong absorption. As can be seen also, the transmittance of $\mathrm{Cu}_{\mathrm{x}} \mathrm{O}$ films increases gradually as the incident angle increases. The transmittance spectrum of copper oxides zigzag GLAD films deposited at $\gamma= \pm 85^{\circ}$ shows a good interference pattern which indicates that the film exhibits an acceptable homogeneity of thickness and a sharp fall of transmittance at the band edge. The degree of slanting at the absorption edge can relate to possible differences in the distribution of defect tail states below the band gap [37].

Based on the reflectance spectra of the $\mathrm{Cu}_{\mathrm{x}} \mathrm{O}$ zigzag thin films, the thickness and the refractive index of the different films deposited respectively at $\gamma= \pm 40^{\circ}, \pm 60^{\circ}, \pm 75^{\circ}$ and $\pm 85^{\circ}$, were calculated from the positions of the interference maxima and minima of reflectance using a standard method [38]. The estimated thicknesses were compared to the ones measured directly by SEM technique, and the values are close. The values of the refractive index in the transparency region and the thickness of the $\mathrm{Cu}_{2} \mathrm{O}$ zigzag films are illustrated in Table 2. We show an obvious change in the refractive index, which may be attributed to the quantum size effect due to the nanocrystallites $\mathrm{Cu}_{\mathrm{x}} \mathrm{O}$. Despite the same deposited quantity of copper, the thickness decreases versus the deposition 
angle from $740 \mathrm{~nm}$ at $\gamma= \pm 40^{\circ}$ to 323 at $\gamma= \pm 85^{\circ}$. Indeed, the bending of the nanosized zigzag becomes more and more important, when the deposition angle increases. For grazing angles of flux deposition, the high degree of bending of the zigzag shapes is reached. Therefore, the bending effect may be the main reason for the thickness decrease. The idea is illustrated in Fig.6. This decrease of the thickness produces less and broad oscillations in the transparency region of the transmittance spectra.

The optical absorption coefficient $\alpha$ of $\mathrm{Cu}_{\mathrm{x}} \mathrm{O}$ zigzag thin films was calculated from the transmittance $T(\lambda)$ and reflectance $R(\lambda)$ data using the following relation [39]:

$$
\alpha=\frac{1}{d} \ln \left(\frac{(1-R)^{2}}{T}\right)
$$

where $d$ is the film thickness. $\mathrm{Cu}_{\mathrm{x}} \mathrm{O}$ zigzag thin films have a high absorption coefficient of $\left(10^{4}-10^{5}\right.$ $\mathrm{cm}^{-1}$ ) in the visible and near-IR spectral range. This result is very important because it is known that the spectral dependence of absorption coefficient affects the solar cells conversion efficiency. To obtain an absorber material with high efficiency, we need a great absorption coefficient within a large spectral range for photovoltaic applications [40]. On the other hand, we notice a shift of the absorption edge towards higher photon energies (Fig.7.a) that is to say that, the oxide phase is favorably promoted with the increase of the deposition angle. Because the oxygen gets into the nanopores easily for high angles and the depth of the pores is more and more accessible when the deposition angles are stronger. In fact, it is well known that the shadowing effect is enhanced when the flux angle deposition increases, therefore the space between the nanostructure motifs or the zigzag nanorods will be more important. As a result, it facilitates the oxygen insertion. This is not very remarkable in the $\mathrm{XRD}$ results, because in most of the cases when the deposition angles are closer to grazing ones, the crystallinity is deteriorated even when we manipulate crystalline phases at the beginning. The second probable reason is the existence of a conflict between the two phases of oxides $\mathrm{Cu}_{2} \mathrm{O}$ and $\mathrm{CuO}$, whereas, for the angle $40^{\circ}$, one has only one dominant phase. We believe that the combined effect of deposition angle and the coexistence of copper oxide phases leads to the 
blue shift of the absorption edge. I. Mukherjee et al. [41] found a similar result for physically selfassembled $\mathrm{Cu}_{2} \mathrm{O}$ nano-column array grown by oblique angle sputter deposition. They explained that the blue shift in nano-columnar structures with high anisotropic crystal orientation could be discussed in terms of the light of Burstein-Moss effect since the loss of charge carriers due to trapping at grain boundaries is expected to be minimized in such structures. This explanation may comfort the fundamental reasons for the already given combined effect.

The extinction coefficient $k$ can be calculated from the relation [42]:

$$
k=\frac{\alpha \lambda}{4 \pi}
$$

where $\alpha$ is the absorption coefficient and $\lambda$ is the wavelength. The variation of extinction coefficient versus wavelength of the $\mathrm{Cu}_{\mathrm{x}} \mathrm{O}$ zigzag thin films deposited at different incident angles is shown in Fig.7 (b). As can be seen, the extinction coefficient decreases with increasing the deposition angle.

The absorption coefficient $\alpha$ can be related to the band gap energy $E_{\mathrm{g}}$ according to the Tauc model [43]:

$$
\alpha h v=A\left(h v-E_{g}\right)^{q}
$$

where $A$ is a constant, $h$ is the Planck constant and $q$ is equal to $1 / 2$ for a direct gap and 2 for an indirect gap semiconductor. The band gap value $E_{\mathrm{g}}$ was determined by extrapolating the linear part of the $(\alpha h v)^{2}$ vs. $h v$ curve to the horizontal photon energy axis (Fig.8). It is clearly seen that the optical band gap increases progressively from $2 \mathrm{eV}$ to $2.54 \mathrm{eV}$ as the deposition angle increases. The band gap values are summarized in Table 2. Based on the XRD study, the increase in the optical band gap with the deposition angle can be attributed to the decrease in crystallite size, which leads to quantum confinement, the quantum size effect as predicted from the nanocrystalline nature of the films. The confinement of the charge carriers in the nanocrystallites results in the increase of a band bending effect and intrinsic microstrain. In our case, the values of the crystallite sizes are in the same order of magnitude. Therefore, it may not contribute significantly to the band gap variation. The measured band gap value using transmittance and reflectance spectra is the effective band gap. According to the Burstein-Moss (B-M) effect, the measured band gap is the sum of B-M 
shift and the intrinsic band gap. This shift allows for the $\mathrm{Cu}_{\mathrm{x}} \mathrm{O}$ thin films empowering considerably the light of a shorter wavelength to be transmitted, making it supportive in enhancement solar cell efficiency.

The Urbach energy $E_{\mathrm{u}}$ or called also Urbach tail is the broadening near the band gap due to the existence within the band gap limit of supplementary density levels with energies, which can give rise to band tailing as has been offered for poor crystalline, disordered and porous materials. In other words, it acts as localized states corresponding to optical transitions between localized states adjacent to the valence band and extended states in the conduction band above the mobility edge. The Urbach energy $E_{\mathrm{u}}$ has been calculated using a linear part of $\ln \alpha$ below the optical band gap using the following expression [44]:

$$
\alpha=\alpha_{0} e^{\left(\frac{h v}{E_{u}}\right)}
$$

where $\alpha_{0}$ is a constant. In fact, Urbach energy $E_{u}$ describes the local defects in the material. The values of $E_{\mathrm{u}}$ for different deposition angles are classified in Table 2, which clearly show that the Urbach energy increases with the increase of incident angles. This result is in good agreement with the XRD results.

The highly oriented nanostructure of the GLAD zigzag films tends to be anisotropic, thus the optical birefringence can be calculated. Fig.9 illustrates the in-plane birefringence of $\mathrm{Cu}_{2} \mathrm{O}$ zigzag thin films deposited at different deposition angles $\gamma$, which is defined as the difference between the two in-plane refractive indices [45], namely $\Delta n=n_{\mathrm{x}}-n_{\mathrm{y}}$. The two in-plane refractive indices $n_{\mathrm{x}}$ and $n_{\mathrm{y}}$ are determined based on the reflectance spectra measured in two orthogonal directions of incident linearly polarized light: $R_{\mathrm{x}}$ is in the x-direction and $R_{\mathrm{y}}$ is in the y-direction. From Fig.9, it is clear that the in-plane birefringence is weak at a low incident angle, then it increases with increasing deposition angle and reaches a maximum value of $\Delta n=0.1063$ at an angle $\gamma= \pm 60$. This maximum of birefringence can be linked to the geometry of the columns. Generally, at deposition angles higher than $60^{\circ}$, the samples have highly porous structures and this tends to reduce the value of the birefringence. As a conclusion, the glancing angle deposition is a promising way to obtain 
larger optical birefringence, and it seems particularly flexible to generate designed devices such as retardation plate and polarizer.

\subsection{Electrical properties}

Fig.10 shows the resistance versus annealing time curves. It exhibits three main parts. Two stages, which represent the two phases metallic and semiconductor, and a vertical rise that separates the two stages, which indicates the metal-semiconductor transition phase. In the first stage, the samples still have their metallic phase. However, they have different resistances as a function of the deposition angle. Moreover, it is noted that the sample deposited at $\gamma= \pm 85^{\circ}$ has the highest resistance, although it is still in the metallic phase, this is due to the favored oxidation process by large pores provided by a high deposition angle. That is why this sample passes rapidly from the metal to semiconductor phase. The phase transition duration decreases as a function of the deposition angle. The oxidation mechanism is easier for high deposition angles since the diffusion of oxygen is controlled by the deposition angle. It is important to note that, the sample deposited at $\gamma= \pm 40^{\circ}$ has the lowest resistance in both stages even after the metal-semiconductor transition phase. Besides, let us recall that the sample deposited at $\gamma= \pm 75^{\circ}$ has two polycrystalline copper oxide phases $\mathrm{Cu}_{2} \mathrm{O}$ and $\mathrm{CuO}$, this is the reason on which we are based to explain the existence of a slight second transition located at 32 min within the semiconductor phase.

In order to study the electrical anisotropy of the zigzag thin films, resistivity measurements were taken between different locations on the sample (Fig.11.a). In Fig.11.b electrical resistances of samples deposited at different incident angles, are shown. It is clear that the electrical resistance increases with increasing deposition angle and reaches a maximum value at an angle of $\pm 60^{\circ}$. After that, it decreases with further increase of the deposition angle.

This abrupt change of electrical properties for GLAD films deposited at incident angles higher than $\pm 60^{\circ}$ is mainly linked to the porous structure, which becomes more and more important for this values of incident angles. Voids between columns may reduce the electron mean free path and 
create barriers potential for the conduction mechanism leading to a drop of the electrical conductivity [46].

\section{Conclusion}

Copper oxide zigzag thin films were successfully prepared on glass substrates by air annealing of copper films deposited using thermal evaporation method at oblique angle deposition. The X-ray diffraction results show that the elaborated films, for all incident angle deposition, have a polycrystalline nature and grown in a preferential orientation along the (111) plane. The crystallite size of the prepared samples decreases with the deposition angle. The deposition angle $\gamma= \pm 40$ seems to be the adequate parameter to create copper oxide zigzag thin films with a good crystalline features. We have shown that the elaborated films have a good absorption coefficient, higher than $10^{5} \mathrm{~cm}^{-1}$ in the visible range and it depicts a blue shift with the deposition angle. Therefore, the band gap increases from $2 \mathrm{eV}$ and $2.54 \mathrm{eV}$, when increasing the deposition angle. The Urbach energy was found to increase from 259 to $534 \mathrm{meV}$ with increasing of incident deposition angle, which probably related to the increase of disorder and the density of defects in the nanostructures. The maximum of birefringence was obtained for an angle $\gamma= \pm 60$. The electrical measurement brings out the electrical anisotropy of the elaborated samples.

\section{References}

[1] Y. Hong, Y. Xing, K. Li, J. Wang, H. Pan, H. Xu, Synthesis of indium nanostructure-laces by multi-step Glancing Angle Deposition, Physica E Low Dimens. Syst. Nanostruct. 60 (2014) 70-74.

[2] F. H. Siyanaki, H. R. Dizaji, M. H. Ehsani, S. Khorramabadi, The effect of substrate rotation rate on physical properties of cadmium telluride films prepared by a glancing angle deposition method, Thin Solid Films 577 (2015) 128-133.

[3] B.D. Polat, O.L. Eryilmaz, R. Erck, O. Keleş, A. Erdemir, K. Amine, Structured SiCu thin films in LiB as anodes, Thin Solid Films, 572 (2014) 134-141. 
[4] B. Gallas, K. Robbie, R. Abdeddaim, G. Guida, Y. Yang, J. Rivory, A. Priou, Silver square nanospirals mimic optical properties of U-shaped metamaterials, Opt. Express 18 (2010) 1633516344.

[5] S. Lee, W. Zhang, F. Khatkhatay, H. Wang, Q. Jia, J. L. MacManus-Driscoll, Ionic conductivity increased by two orders of magnitude in micrometer-thick vertical Yttria-stabilized $\mathrm{ZrO}_{2}$ nanocomposite films, Nano Lett., 15 (2015) 7362-7369.

[6] A. Sinaoui, F. Chaffar-Akkari, B. Gallas, D. Demaille, M. Kanzari, Investigation of growth and characterization of nanostructured $\mathrm{CuIn}_{5} \mathrm{~S}_{8}$ thin films produced by glancing angle deposition, Thin Solid Films 590 (2015) 111-117.

[7] S.Z. Rahchamani, H.R. Dizaji, M.H. Ehsani, Study of structural and optical properties of ZnS zigzag nanostructured thin films, Appl. Surf. Sci. 356 (2015) 1096-1104.

[8] S. Wang, G. Xia, H. Hea, K. Yia, J. Shao, Z. Fan, Structural and optical properties of nanostructured $\mathrm{TiO}_{2}$ thin films fabricated by glancing angle deposition, J. Alloy. Compd. 431 (2007) 287-291.

[9] Y. Zhou, T. Taima, T. Miyadera, T. Yamanari, M. Kitamura, K. Nakatsu, Y. Yoshida, Glancing Angle Deposition of copper iodide nanocrystals for efficient organic photovoltaics, Nano Lett. 12 (2012) 4146-4152.

[10] M.M. Hawkeye, M.J. Brett, Optimized colorimetric photonic-crystal humidity sensor fabricated using Glancing Angle Deposition, Adv. Funct. Mater 21 (2011) 3652-3658.

[11] M.M. Hawkeye, R. Joseph, J.C. Sit, M.J. Brett, Coupled defects in one-dimensional photonic crystal films fabricated with glancing angle deposition, Opt. Express 18 (2010) 13220-13226.

[12] M. Horprathum, K. Limwichean, A. Wisitsoraat, P. Eiamchai, K. Aiempanakit, P. Limnonthakul, N. Nuntawong, V. Pattantsetakul, A. Tuantranont, P. Chindaudom, $\mathrm{NO}_{2}$-sensing properties of $\mathrm{WO}_{3}$ nanorods prepared by glancing angle DC magnetron sputtering, Sens. Actuators B-Chem. 176 (2013) 685-691. 
[13] M. Samadi, M. Zirak, A. Naseri, E. Khorashadizade, A. Z. Moshfegh, Recent progress on doped ZnO nanostructures for visible-light photocatalysis, Thin Solid Films 605 (2016) 2-19.

[14] A. Barranco, A. Borras, A.R. Gonzalez-Elipe, A. Palmero, Perspectives on oblique angle deposition of thin films: From fundamentals to devices, Prog. Mater. Sci. 76 (2016) 59-153.

[15] C. Yang, J. Wang, F. Xiao, X. Su, Microwave hydrothermal disassembly for evolution from $\mathrm{CuO}$ dendrites to nanosheets and their applications in catalysis and photo-catalysis, Powder Technol. 264 (2014) 36-42.

[16] A. Umar, A.A. Alshahrani, H. Algarni, R. Kumar, CuO nanosheets as potential scaffolds for gas sensing applications, Sens. Actuators B-Chem. 250 (2017) 24-31.

[17] W. Wang, X. Huang, Sh. Wu, Y. Zhou, L. Wang, H. Shi, Y. Liang, B. Zou, Preparation of p-n junction $\mathrm{Cu}_{2} \mathrm{O} / \mathrm{BiVO}_{4}$ heterogeneous nanostructures with enhanced visible-light photocatalytic activity, Appl. Catal. B: Environ. 134 (2013) 293-301.

[18] J. Gan, V. Venkatachalapathy, B.G. Svensson, E.V. Monakhov, Influence of target power on properties of $\mathrm{Cu}_{\mathrm{x}} \mathrm{O}$ thin films prepared by reactive radio frequency magnetron sputtering, Thin Solid Films 594 (2015) 250-255.

[19] M. Heinemann, B. Eifert, C. Heiliger, Band structure and phase stability of the copper oxides $\mathrm{Cu}_{2} \mathrm{O}, \mathrm{CuO}$, and $\mathrm{Cu}_{4} \mathrm{O}_{3}$, Phys. Rev. B 87 (2013) 115111

[20] F.K. Mugwang'a, P.K. Karimi, W.K. Njoroge, O. Omayio, S.M. Waita, Optical characterization of Copper Oxide thin films prepared by reactive dc magnetron sputtering for solar cell applications, Int. J. Thin Film Sci.Tec. 2 (2013) 15-24.

[21] D.S.C. Halin, K.R. Ahmad, K. Hussin, I.A. Talib, A.R. Daud, M.A.A. Hamid, A.V. Sandu, Characterization of cuprous oxide thin films prepared by sol-gel spin coating technique with different additives, Applied Mechanics and Materials 754 (2015) 1141-1145.

[22] L. De Los Santos Valladares, D. Hurtado Salinas, A. Bustamante Dominguez, D. Acosta, Najarro, S.I. Khondaker, T. Mitrelias, C.H.W. Barnes, J. Albino Aguiar, Y. Majima, Crystallization 
and electrical resistivity of $\mathrm{Cu}_{2} \mathrm{O}$ and $\mathrm{CuO}$ obtained by thermal oxidation of $\mathrm{Cu}$ thin films on $\mathrm{SiO}_{2} / \mathrm{Si}$ substrates, Thin Solid Films 520 (2012) 6368-6374.

[23] T. Mahalingam, J. S. P. Chitra, S. Rajendran, M. Jayachandran, M. J. Chockalingam, Galvanostatic deposition and characterization of cuprous oxide thin films, J. Cryt. Growth 216 (2000) 304-310.

[24] A. Chen, H. Long, X. Li, Y. Li, G. Yang, P. Lu, Controlled growth and characteristics of single-phase $\mathrm{Cu}_{2} \mathrm{O}$ and $\mathrm{CuO}$ films by pulsed laser deposition, Vacuum 83 (2009) 927-930.

[25] V. Saravanan, P. Shankar, G. K. Mani, J. Bosco, B. Rayappan, Growth and characterization of spray pyrolysis deposited copper oxide thin films: Influence of substrate and annealing temperatures, J. Anal. Appl. Pyrolysis. 111 (2015) 272-277

[26] F. Chaffar Akkari, M. Kanzari, Optical, structural, and electrical properties of $\mathrm{Cu}_{2} \mathrm{O}$ thin films, Phys. Status Solidi A 207 (2010)1647-1651.

[27] N. Tounsi, A. Barhoumi, F. Chaffar Akkari, M. Kanzari, H. Guermazi, S. Guermazi, Structural and optical characterization of copper oxide composite thin films elaborated by GLAD technique, Vacuum 121 (2015) 9-17.

[28] W. Mingzhen, H. Jianzhen, Preparation of $\mathrm{Cu}_{2} \mathrm{O}$ nanorods by a simple solvothermal method, Mater. Chem. Phys. 121 (2010) 291-294.

[29] Z. Cheng, J. Xu, H. Zhong, X-Zhong Chu, J. Song, Repeatable synthesis of $\mathrm{Cu}_{2} \mathrm{O}$ nanorods by a simple and novel reduction route, Mater. Lett. 65 (2011) 1871-1874.

[30] M. Sabbaghan, J. Beheshtian, R-N. Liarjdame, Preparation of $\mathrm{Cu}_{2} \mathrm{O}$ nanostructures by changing reducing agent and their optical properties, Mater. Lett. 153 (2015) 1-4.

[31] Y. Lv, B. Shi, X. Su, Y. Li, J. Sun, J. Shao, L. Tian, J. Ding, Fabrication and characterisation of $\mathrm{Cu}_{2} \mathrm{O}$ nanorods array by anodic oxidation method, Micro Nano Lett. 13 (2018) 289-291.

[32] U. Nerle, M. K. Rabinal, Thermal oxidation of copper for favorable formation of cupric oxide (CuO) semiconductor, IOSR-J. A. P. 5 (2013) 01-07. 
[33] W.G. Lee, Electrical resistance evolution of $\mathrm{Cu}$ redistribution layer electroplated on a $\mathrm{Si}$ interposer, Int. J. Metall. Mater. Eng. 1 (2015) 116-125.

[34] S.F. Bartram, Handbook of X-Rays, ed. by E.F. Kaelebe, McGraw-Hill, New York, 1967.

[35] P. Karen, P.M. Woodward, Liquid-mix disorder in crystalline solids: $\mathrm{ScMnO}_{3}$, J. Solid State Chem. 141 (1998) 78-88.

[36] T. Theivasanthi, M. Alagar, Electrolytic synthesis and characterization of silver nanopowder, Nano Biomed. Eng. 4 (2012) 58-65.

[37] C. M. Muiva, A. O. Juma, L. M. Lepodise, K. Maabong, D. Letsholathebe, Surfactant-assisted chemical bath deposition based synthesis of 1-D nanostructured $\mathrm{CuO}$ thin films from alkaline baths, Mater. Sci. Semicond. Process. 67 (2017) 69-74.

[38] K.L Chopra, Thin film phenomena, Mc Graw-Hill, New York, 721 (1969).

[39] D. Abdelkader, M. Ben Rabeh, N. Khemiri, M. Kanzari, Investigation on optical properties of $\mathrm{Sn}_{\mathrm{x}} \mathrm{Sb}_{\mathrm{y}} \mathrm{S}_{\mathrm{z}}$ sulfosalts thin films, Mater. Sci. Semicond. Process., 21 (2014) 14-19.

[40] M. Caglar, S. Ilican, Y. Caglar, F. Yakuphanoglu, The effects of Al doping on the optical constants of $\mathrm{ZnO}$ thin films prepared by spray pyrolysis method, J. Mater. Sci.: Mater. Electron.19 (2008) 704-708.

[41] I. Mukherjee, S. Chatterjee, N-A. Kulkarni, Band gap tuning and room-temperature photoluminescence of a physically self-assembled $\mathrm{Cu}_{2} \mathrm{O}$ nanocolumn array, J. Phys. Chem. C 120 (2016) 1077-1082.

[42] V.V. Kindyak, V.F. Gremenonok, I.V. Bodnar, V. Rud Yu, G.A. Madvedkin, Optical properties of laser-evaporated $\mathrm{CuGaSe}_{2}$ films near and above the fundamental absorption edge, Thin Solid Films 250 (1994) 33-36.

[43] J. Tauc, Amorphous and Liquid Semiconductors, Plenum Press, London, New York, 1974.

[44] S. Zaynobidinov, R.G. Ikramov, R.M. Jalalov, Urbach energy and the tails of the density of states in amorphous semiconductors, J. Appl. Spectrosc. 78 (2011) 223-227.

[45] G. Beydaghyan, K. Kaminska, T. Brown, K. Robbie, Enhanced birefringence in vacuum 
evaporated silicon thin films, Appl. Opt. 43 (2004) 5343-5349.

[46] V. Collado, N. Martin, P. Pedrosa, J.Y. Rauch, M. Horakova, M.A.P. Yazdi, A. Billard, Temperature dependence of electrical resistivity in oxidized vanadium films grown by the GLAD technique, Surf. Coat. Technol. 304 (2016) 476-485. 


\section{Figures and tables captions}

Fig. 1: The schematic diagram of the GLAD technique for the synthesis of zigzag $(+\gamma,-\gamma)$ nanostructures.

Fig. 2: $\mathrm{SEM}$ images of (a) $\mathrm{Cu}$ zigzag nanostructures deposited at $\gamma= \pm 85^{\circ}$ and (b) $\gamma= \pm 60^{\circ}$ (c) $\mathrm{Cu}_{2} \mathrm{O}$ zigzag nanostructures deposited at $\gamma= \pm 85^{\circ}$ and (d) $\gamma= \pm 60^{\circ}$.

Fig. 3: SEM cross-section images taken at a tilt angle of $3.5^{\circ}$ (a) $\mathrm{Cu}$ zigzag nanostructures deposited at $\gamma= \pm 85^{\circ}$ with a magnification of $101.91 \mathrm{~K} \times$ and (b) $3.537 .56 \mathrm{~K} \times$ (c) SEM crosssection images taken at a tilt angle of $14.7^{\circ}$ of the $\mathrm{Cu}_{2} \mathrm{O}$ film deposited at $\gamma= \pm 85^{\circ}$ with a magnification of $103.36 \mathrm{~K} \times$ and (d) $62.75 \mathrm{~K} \times$.

Fig. 4: (a) X-ray diffraction patterns of Copper oxide zigzag thin films deposited at different incident angles and (b) Evolution of $\mathrm{I}_{111} / \mathrm{I}_{200}$ ratio, $\mathrm{I}_{111}$ and strain $\varepsilon$ function of deposition angle.

Fig. 5: Optical transmittance and reflectance spectra of the copper oxide zigzag thin films function of deposition angle.

Fig. 6: Effect of the deposition angle on the bending of the zigzag motif.

Fig. 7: (a) Absorption and (b) extinction coefficients of copper oxide zigzag thin films deposited at different deposition angles.

Fig. 8: Direct band gap energy of copper oxide zigzag thin film deposited at $\gamma= \pm 85^{\circ}$.

Fig. 9: Variation of birefringence $\Delta n$ as a function of deposition angle.

Fig. 10: Variation of electrical resistance versus annealing time of copper oxide zigzag thin film deposited at different incident angles.

Fig. 11: (a) Layer configuration for the electrical measurements and (b) Variation of electrical resistance at a different position in the copper oxide zigzag thin film deposited at different incident angles.

Table 1: Estimated values of structural parameters for the copper oxide zigzag thin film deposited at different incident angles.

Table 2: Thickness, refractive index, band gap and Urbach energy values of copper oxide zigzag thin films deposited at different incident angles. 
Table 1

\begin{tabular}{|c|c|c|c|}
\hline Deposition angle $\gamma\left({ }^{\circ}\right)$ & $\begin{array}{c}\text { Crystallite size (nm) } \\
\text { Scherrer's method }\end{array}$ & $\begin{array}{c}\text { Crystallite size } D_{\mathrm{WH}} \\
(\mathrm{nm})\end{array}$ & Strain $\varepsilon\left(\times 10^{-3}\right)$ \\
\hline $\pm 40^{\circ}$ & 15 & 27 & 8.63 \\
\hline $\pm 60^{\circ}$ & 14 & 26 & 11.79 \\
\hline $\pm 75^{\circ}$ & 13 & 24 & 13.08 \\
\hline $\pm 85^{\circ}$ & 13 & 21 & 11.45 \\
\hline
\end{tabular}


Table 2

\begin{tabular}{cccccc}
\hline \multirow{2}{*}{$\begin{array}{c}\text { Deposition } \\
\text { angle } \boldsymbol{\gamma}\left(^{\circ}\right)\end{array}$} & $\begin{array}{c}\text { FEM } \\
\text { measurement }\end{array}$ & $\begin{array}{c}\text { Optical } \\
\text { measurement }\end{array}$ & $\begin{array}{c}\text { Refractive } \\
\text { index }\end{array}$ & $\boldsymbol{E}_{\mathbf{g}}(\mathbf{e V})$ & $\boldsymbol{E}_{\mathbf{u}}(\mathbf{m e V})$ \\
\hline $\mathbf{\pm 4 0 ^ { \circ }}$ & 735 & 740 & 2.52 & 2.00 & 259 \\
$\mathbf{\pm 6 0}^{\circ}$ & 479 & 454 & 2.62 & 2.44 & 343 \\
$\mathbf{\pm 7 5}^{\circ}$ & 382 & 376 & 2.42 & 2.45 & 427 \\
$\mathbf{\pm 8 5}^{\circ}$ & 341 & 323 & 2.61 & 2.54 & 534 \\
\hline
\end{tabular}




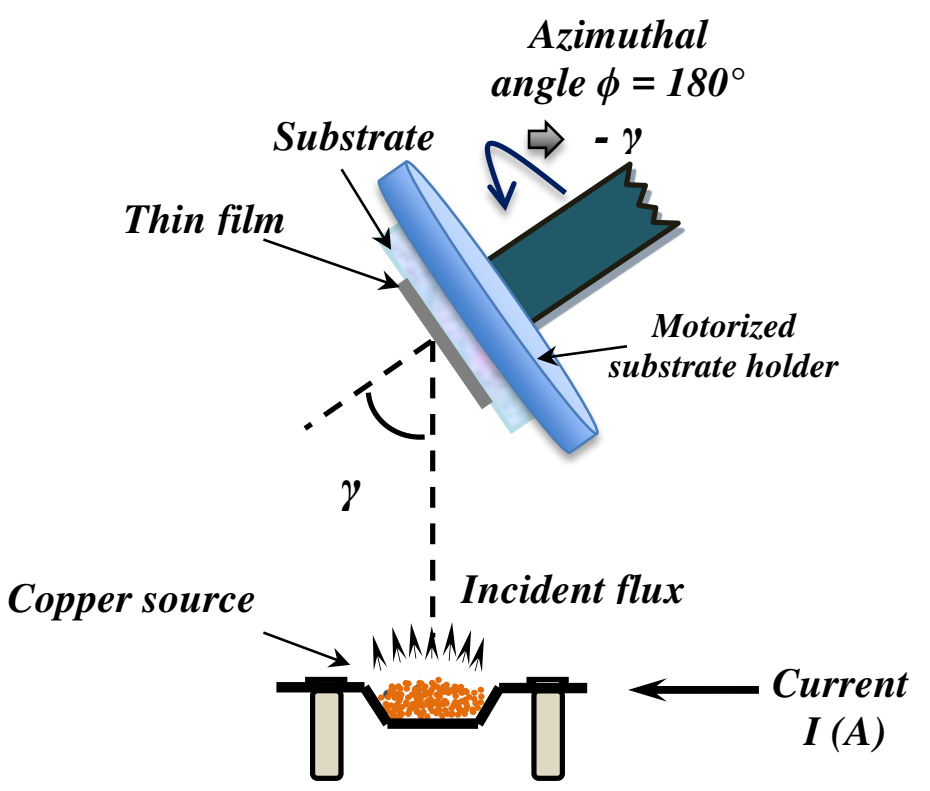

Fig. 1 

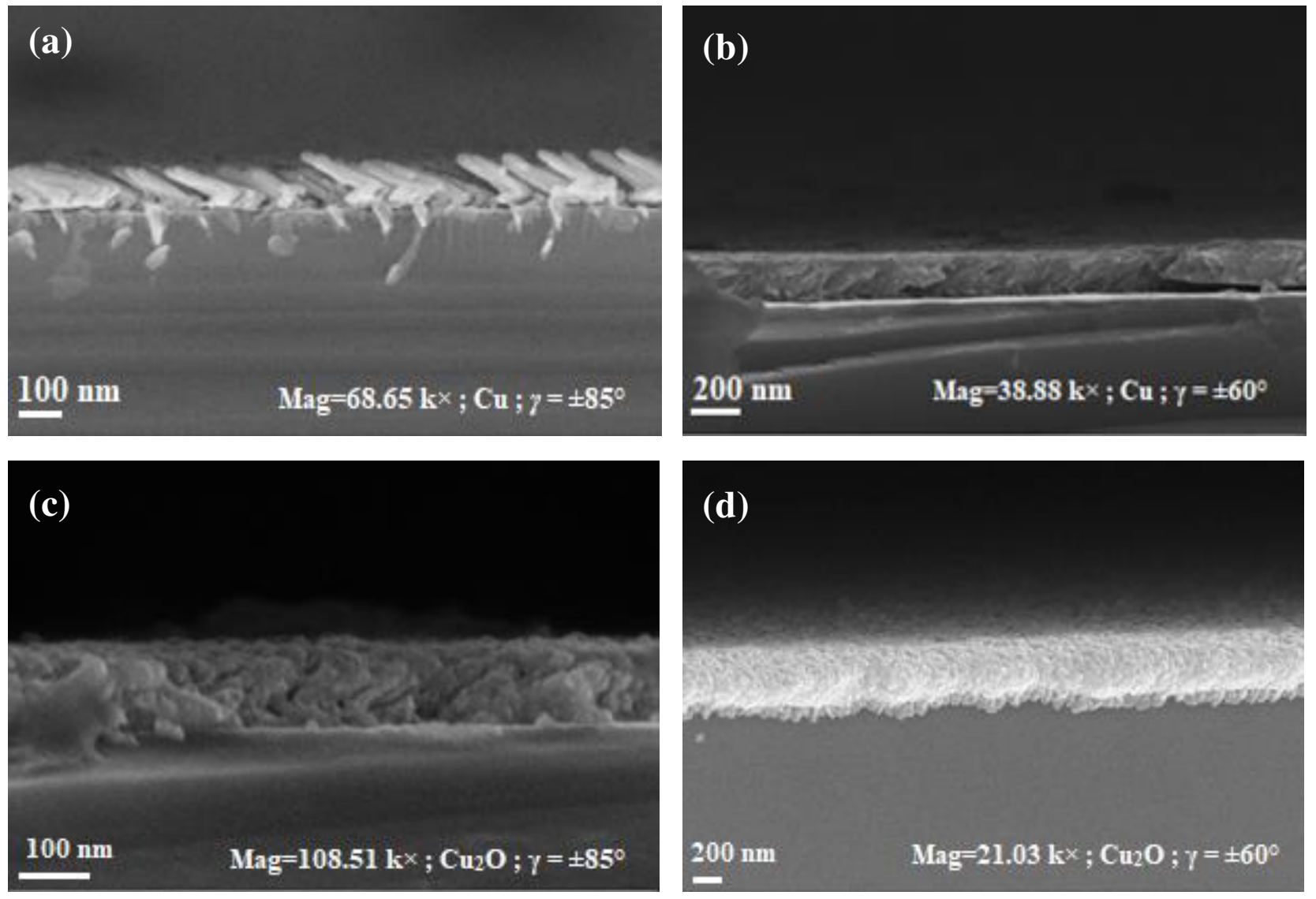

Fig. 2 

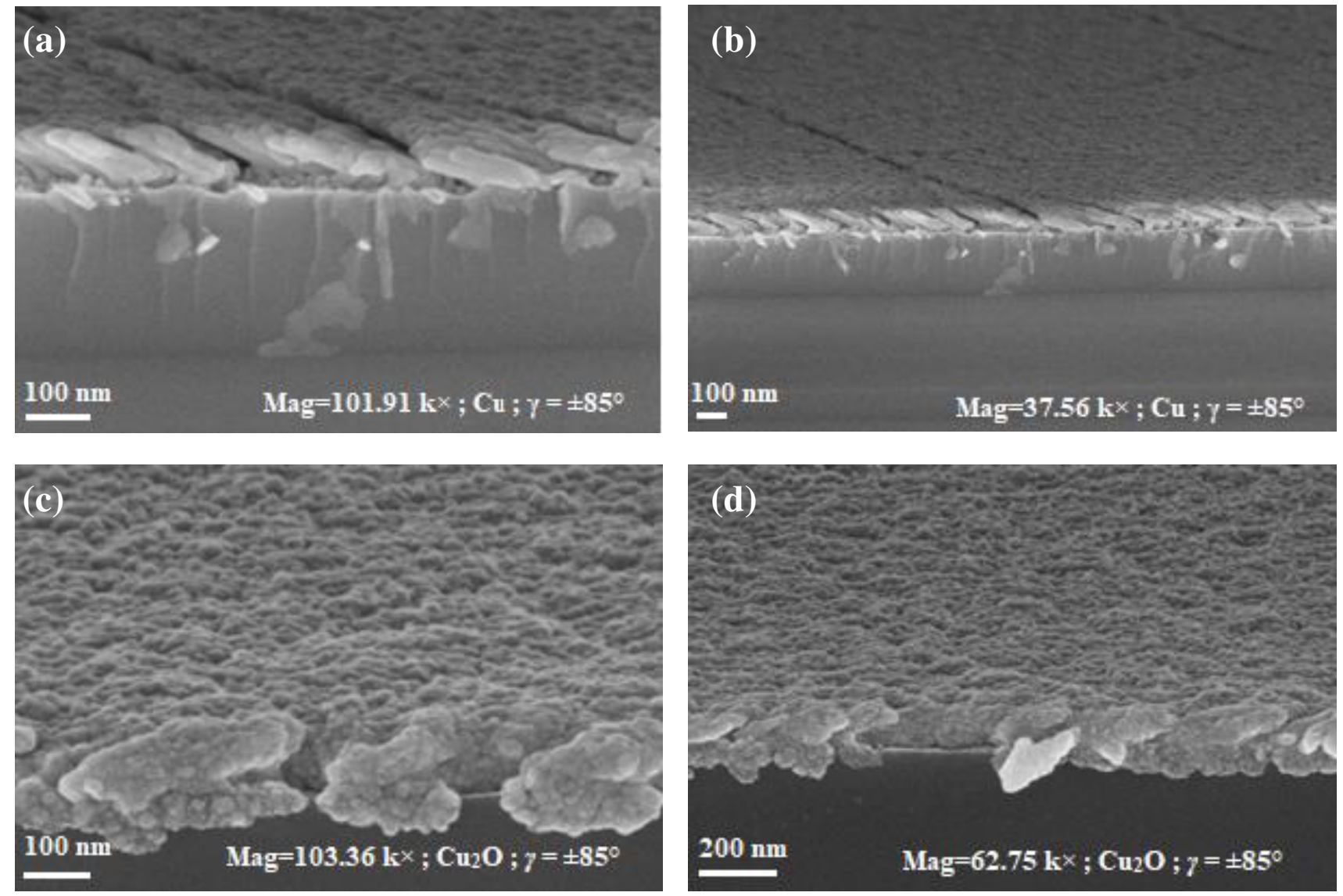

Fig. 3 

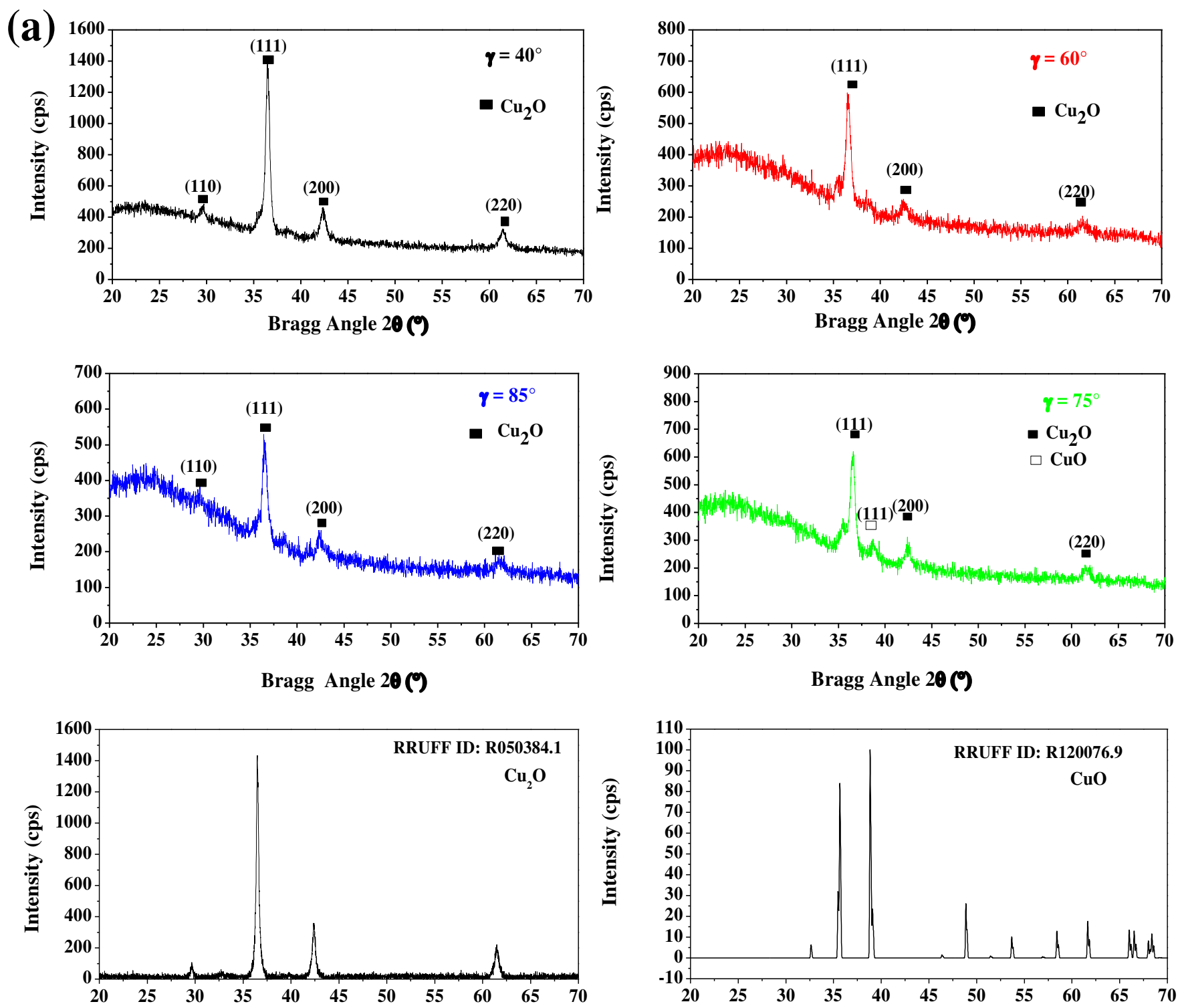

(b)
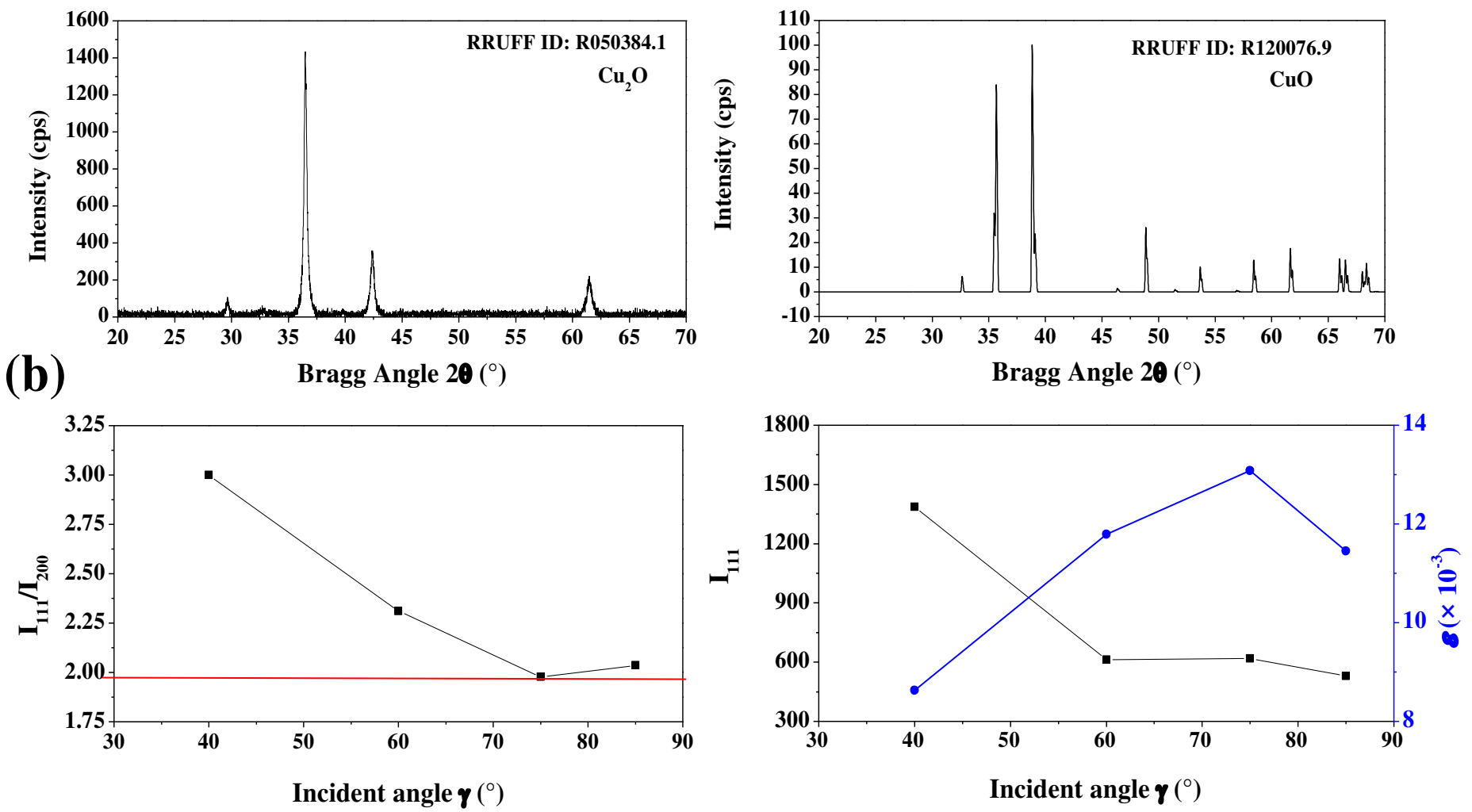

Fig. 4 

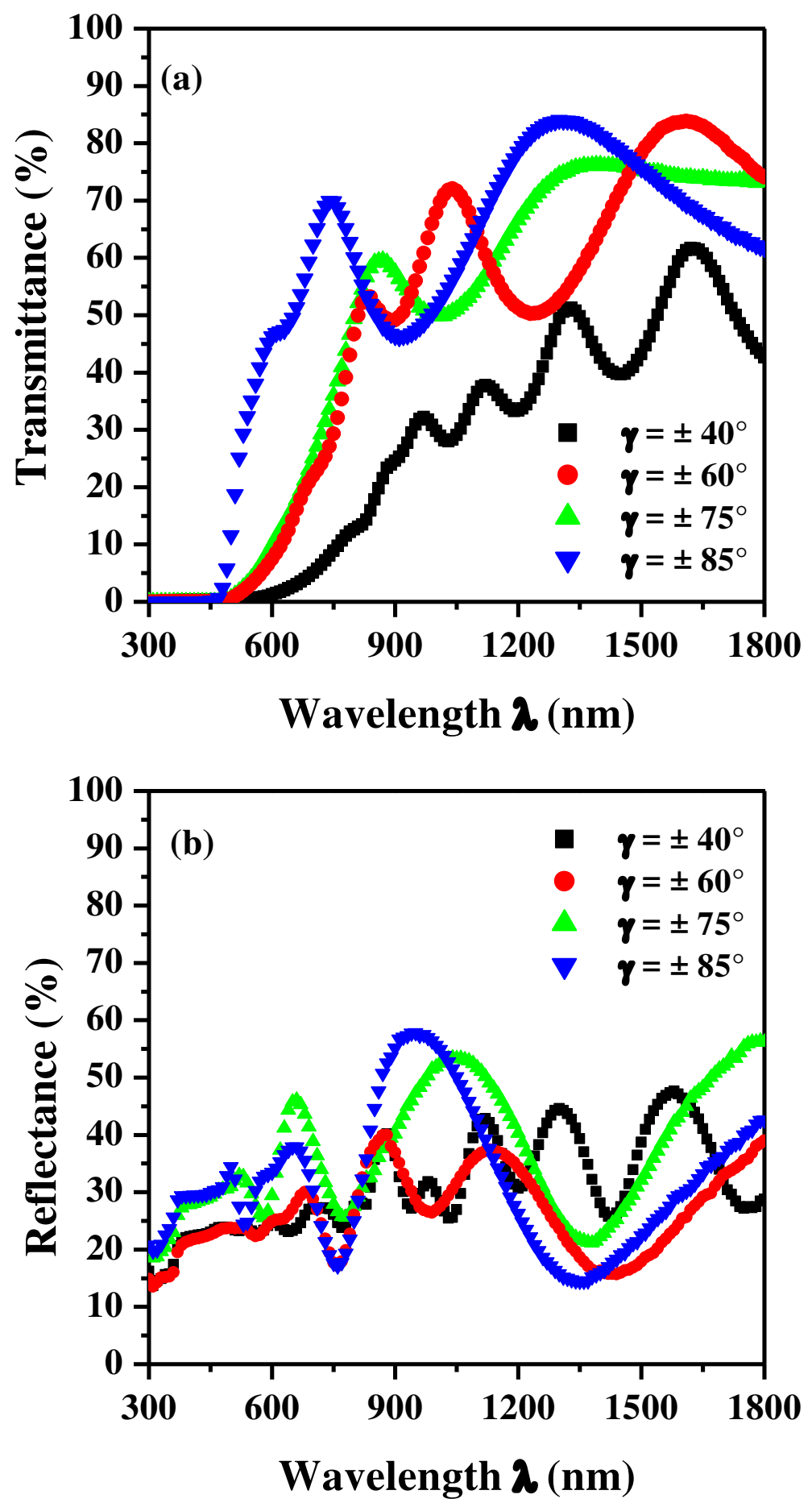

Fig. 5 


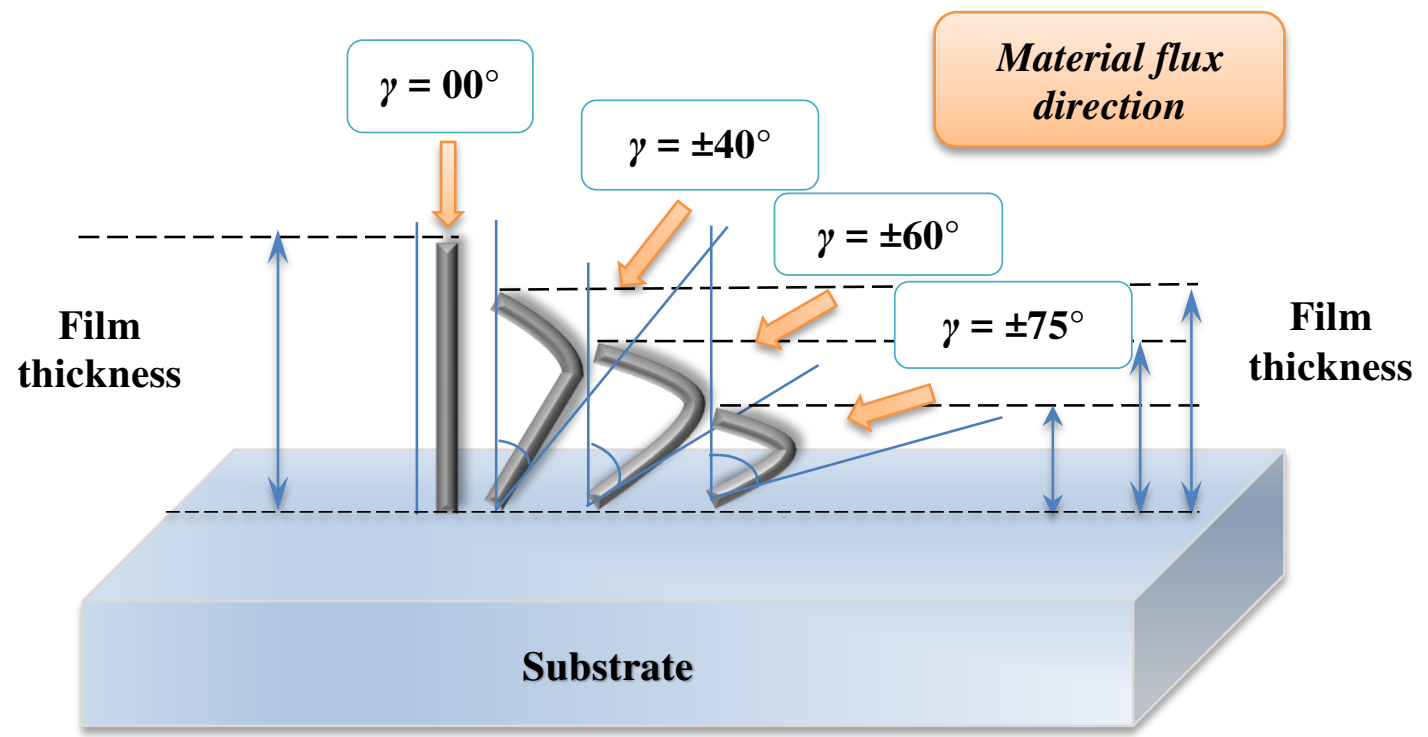

Fig. 6 


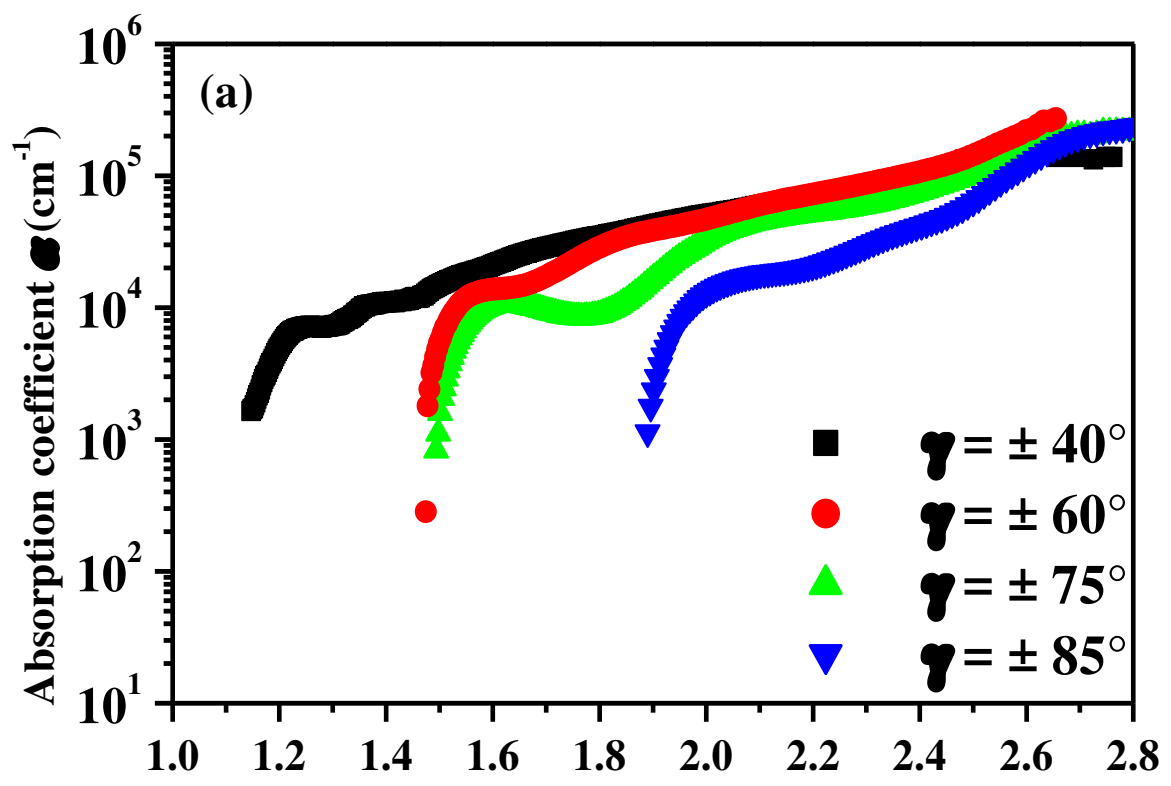

Photon energy hv (eV)

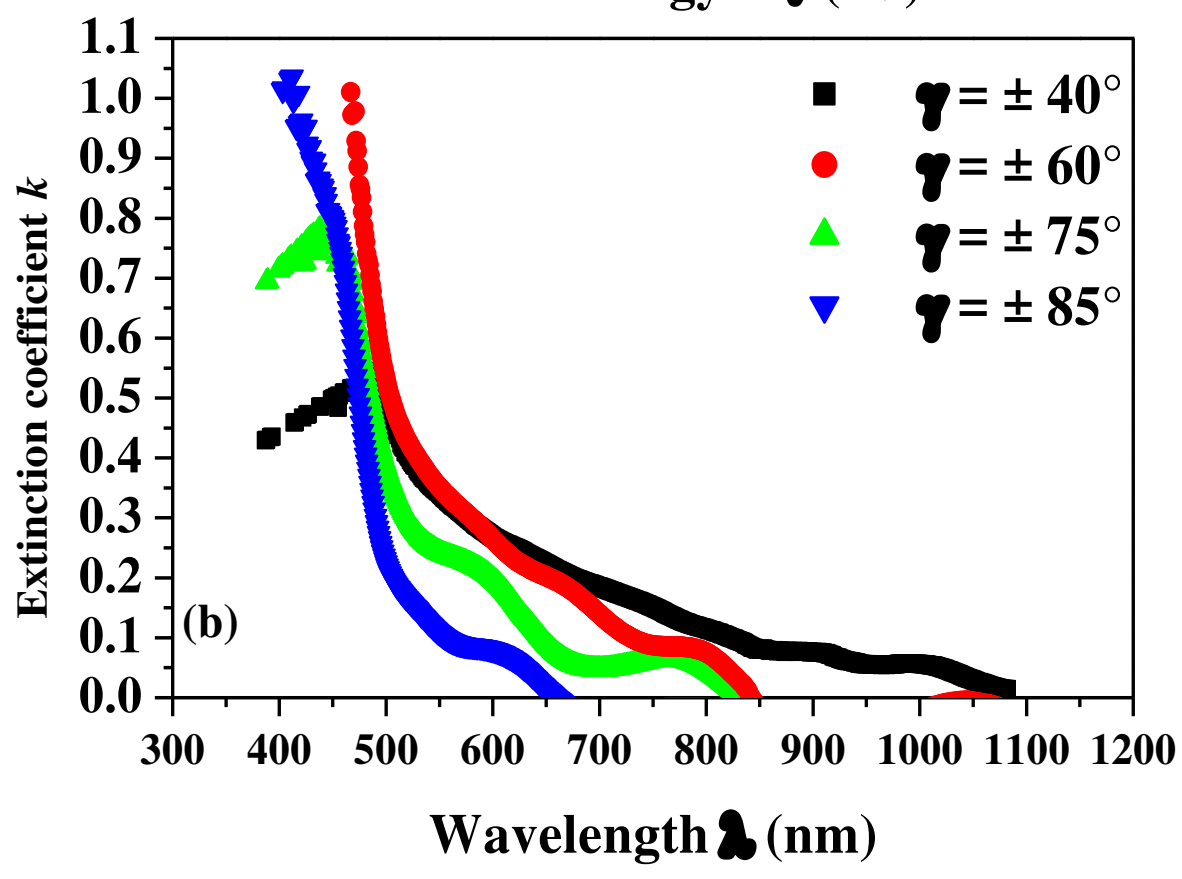

Fig. 7 


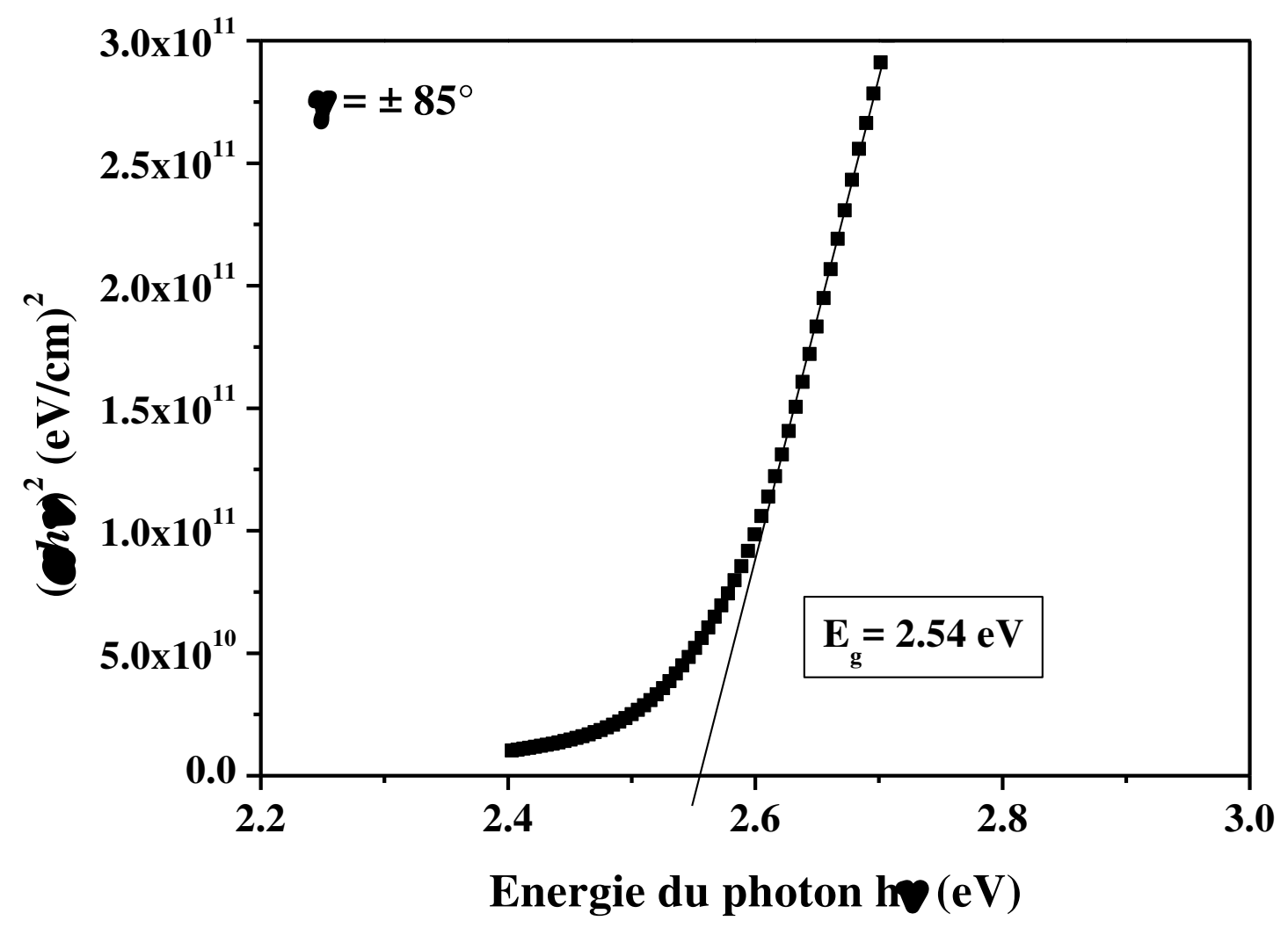

Fig. 8 


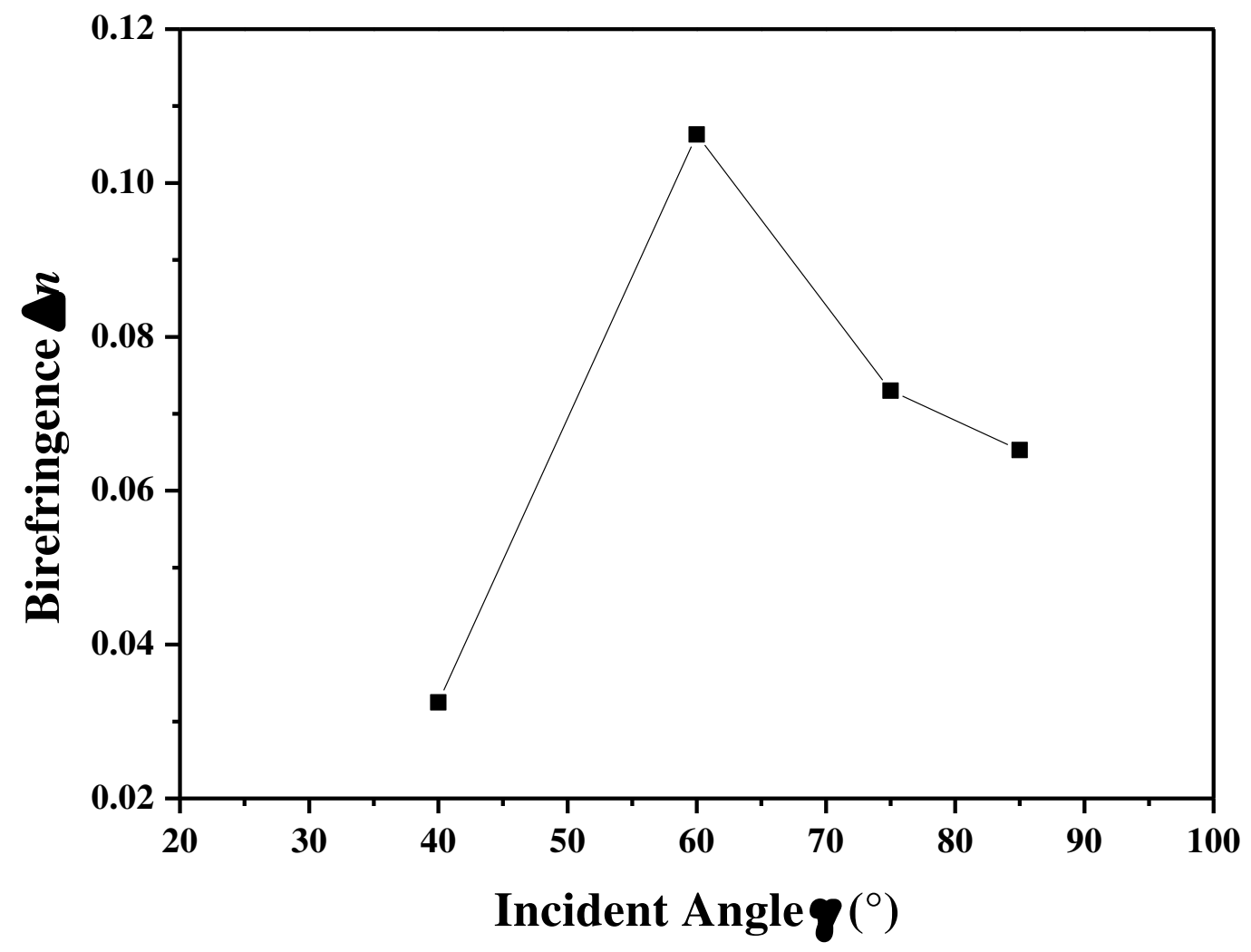

Fig. 9 


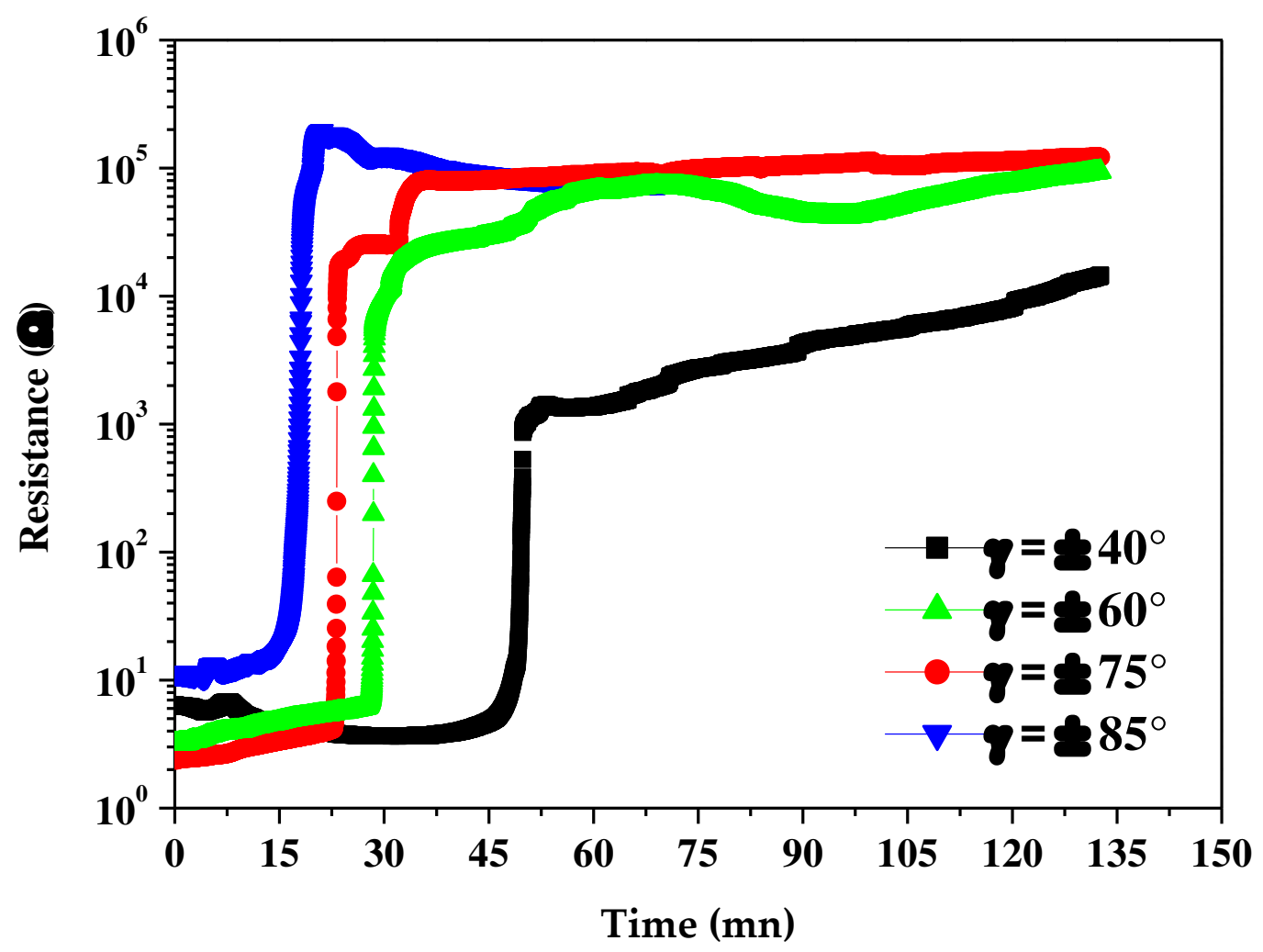

Fig. 10 
(a)

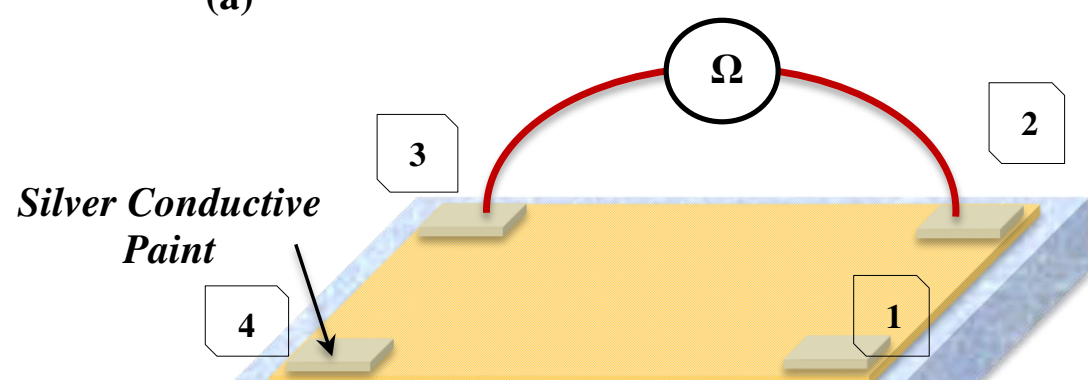

Substrate

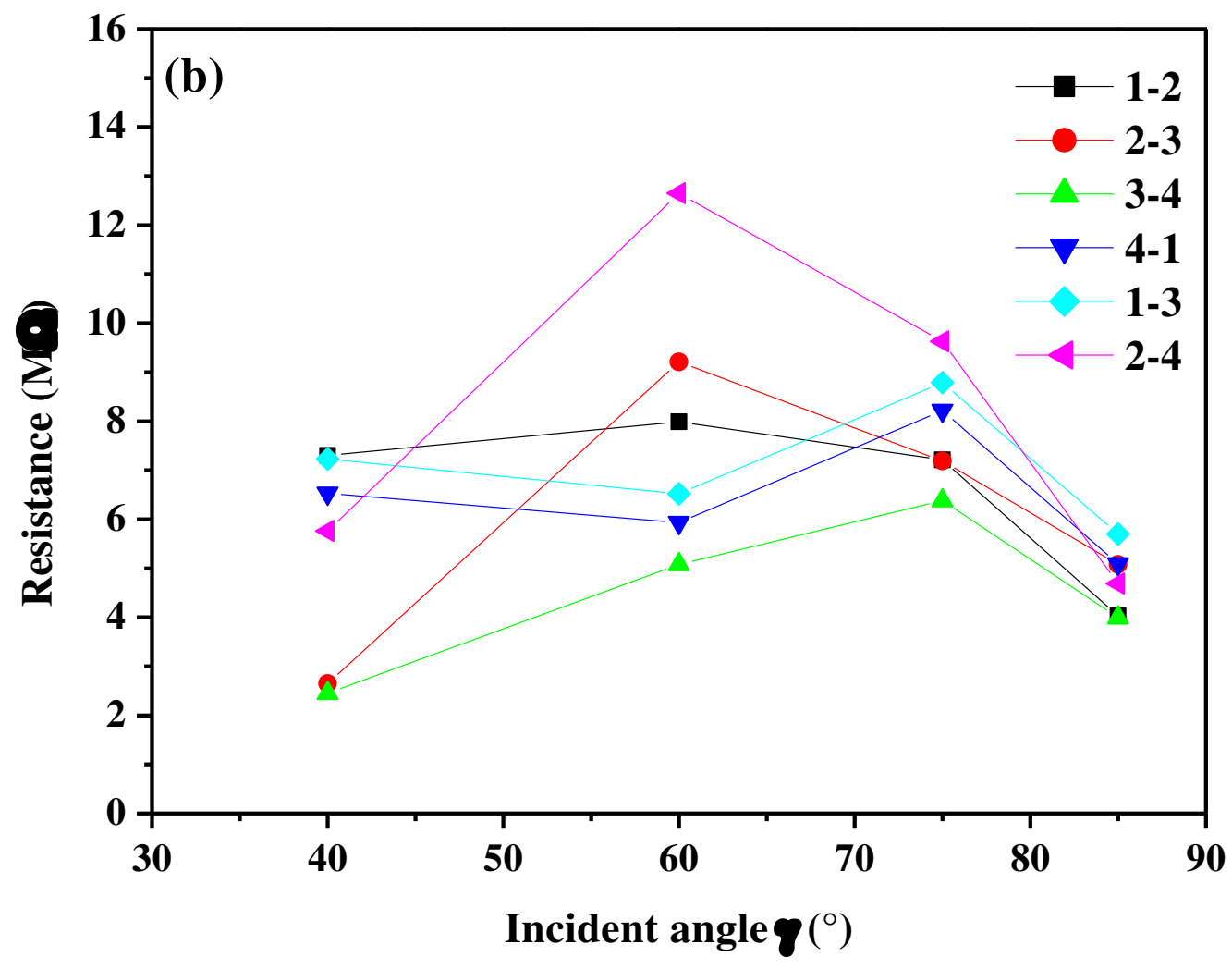

Fig. 11 